\title{
Carotid artery stenting with Roadsaver stent. Early and four-year results from a single-center registry
}

\author{
Roman A. Machnik ${ }^{1}$, Piotr Pieniążek ${ }^{1,2}$, Marcin Misztal ${ }^{1}$, Krzysztof Plens ${ }^{3}$, Marek Kazibudzki ${ }^{1}$, \\ Tomasz Tomaszewski ${ }^{4}$, Andrzej Brzychczy ${ }^{1}$, Robert Musiał ${ }^{5}$, Mariusz Trystuła ${ }^{1}$, tukasz M. Tekieli ${ }^{2}$ \\ ${ }^{1}$ Department of Vascular Surgery and Endovascular Interventions, John Paul II Hospital, Krakow, Poland \\ ${ }^{2}$ Department of Interventional Cardiology, Institute of Cardiology, Jagiellonian University, Medical College, John Paul II Hospital, Krakow, Poland \\ ${ }^{3} \mathrm{KCRI}$, Krakow, Poland \\ ${ }^{4}$ Department of Neurology, John Paul II Hospital, Krakow, Poland \\ ${ }^{5}$ Department of Anesthesiology and Intensive Medical Therapy, John Paul II Hospital, Krakow, Poland
}

Adv Interv Cardiol 2020; 16, 4 (62): 444-451

DOI: https://doi.org/10.5114/aic.2020.101770

\begin{abstract}
A bstract
Introduction: Prevention of peri- and postprocedural complications is still a challenge in carotid artery stenting (CAS).

Aim: To assess immediate and long-term safety and effectiveness of CAS using the Roadsaver double-nitinol-layer-micromesh stent.

Material and methods: Since 2014, 298 CAS procedures in 287 non-consecutive patients (203 men, mean age $70.5 \pm 8.6$ years, $100 \%$ symptomatic/high risk lesions) have been performed using the Roadsaver stent and proximal (40\%) or distal (60\%) neuroprotection system. Clinical and neurological examinations as well as duplex ultrasound were completed before CAS, before discharge, at 1,6 and 12 months, then annually.

Results: All CAS procedures were successful. Carotid stenosis was reduced from $84.9 \pm 9.9 \%$ to $11.0 \pm 9.4 \%(p<000.1)$. In hospital, 1 ipsilateral periprocedural major $(0.3 \%)$ and 3 minor $(1.34 \%)$ ischemic strokes occurred, $2(0.7 \%)$ patients died due to a cerebral hemorrhage on day 9 and 21 . Three (1.0\%) additional ipsilateral minor strokes within 30 consecutive days occurred. Thus, 30-day complications were observed in 9 (3.0\%) patients. Two minor strokes were associated with in-stent thrombosis (0.7\%). The 4-year follow-up showed $82 \%$ overall survival ( $95 \% \mathrm{Cl}$ : $69-91 \%)$ with no significant difference between asymptomatic (77\%) and symptomatic patients $(97 \% ; p=0.076)$. The stroke-free survival was $89 \%(95 \% \mathrm{Cl}: 77-95 \%), 84 \%$ asymptomatic vs. $98 \%$ symptomatic $(p=0.187)$. Seven $(2.3 \%)$ patients developed $>50 \%$ in-stent restenosis.

Conclusions: Carotid artery stenting using the Roadsaver stent for symptomatic patients and high risk lesions showed to be safe and effective, with a low complication rate and acceptable in-stent restenosis risk in 4-year follow-up.
\end{abstract}

Key words: carotid artery stenting, Roadsaver stent, nitinol double-layer micromesh stent.

Su m m a ry

We aimed to assess immediate and long-term safety and effectiveness of carotid artery stenting (CAS) using the Roadsaver double-nitinol-layer-micromesh stent in 287 non-consecutive patients. All CAS were performed using the proximal $(40 \%)$ or distal $(60 \%)$ neuroprotection system. Clinical and neurological examination as well as duplex ultrasound were completed before CAS, before discharge, at 1, 6 and 12 months, then annually. All CAS procedures were successful. In 30 days major complications (stroke/death) were observed in 9 (3.0\%) patients. The 4-year follow-up showed $82 \%$ overall survival with no significant difference between asymptomatic and symptomatic patients. The stroke-free survival was $89 \%$. Seven (2.3\%) patients developed $>50 \%$ in-stent restenosis.

\section{Introduction}

Effectiveness and safety of CAS as well as CEA in primary and secondary prevention of stroke have been demonstrated in high-volume cohorts of patients with carotid artery stenosis [1]. The CREST trial in patients with symptomatic and asymptomatic carotid artery

\section{Corresponding author:}

Łukasz M. Tekieli MD, PhD, Department of Interventional Cardiology, Institute of Cardiology, Jagiellonian University, Medical College, John Paul II Hospital, Krakow, Poland, phone: +48 607414 446, e-mail: Itekieli@szpitaljp2.krakow.pl

Received: 4.09.2020, accepted: 19.10.2020. 
stenosis confirmed similar outcomes for CAS and CEA in the primary endpoint (stroke, death, myocardial infarction) but showed relative excess of minor stroke by 30 days - mainly postprocedural - after CAS [2-4]. The risk of embolization as a result of plaque protrusion and releasing debris is greatest after removal of an embolic protection device (EPD) and persists for at least 30 days until full endothelization of the stent [3-6]. It has been shown in several large-scale trials that the risk of releasing debris through the stent struts and distal embolization is significantly higher with open-cell stents as compared to closed-cell stents $[3,7,8]$. On the other hand, proper, individual-based selection of patients and wide use of proximal neuroprotection devices made it possible to achieve a complication rate of $1 \%$ if 'small' open-cell designed stents are in use for patients with tortuous vessels and non-high-risk lesions [9]. In a search of compromise between open-cell and closed-cell designed stents, novel technology of stent architecture has been developed - by adding an extra micromesh layer to the standard open-cell or close-cell nitinol skeleton. Thus, it was possible to decrease the stent cell area to $0.38 \mathrm{~mm}^{2}$ (Roadsaver, Terumo, Japan) or $0.15 \mathrm{~mm}^{2}$ (CGuard, InspireMD, Israel). As this technology is relatively new there have been still concerns about the safety and long-term durability of dual layer micromesh-covered stents (DLMCS) in carotid artery stenting procedures. Some encouraging data on immediate results of DLMCS implantation have already been collected $[3,10]$.

\section{Aim}

Assessment of immediate and long-term safety and efficacy of carotid artery stenting using Roadsaver stent in the treatment of symptomatic or high-risk, extracranial carotid artery stenosis.

\section{Material and methods}

This is a retrospective analysis of 298 non-consecutive DLMCS-supported CAS procedures in 287 patients (including 11 patients who underwent bilateral CAS) performed between 2014 and 2019. All treated carotid lesions ( $>50 \%$ in direct angiography by quantitative angiography - QA) were symptomatic (89, 30\%; ipsilateral stoke and/or transient ischemic attack in the last 6 months) or high-risk by morphology (209, 70\%; echolucent, highly lipidic, thrombus-containing, ulcerated and "stringsign") [11]. Most of the patients were men (203, 70.7\%) and average age was $70.5 \pm 8.6$ years (range: $51-88$ ). Detailed group characteristics are provided in Table I.

In each patient routinely computed tomography (CT) scan of the head was performed as a part of independent neurological evaluation before carotid intervention. The severity of stenosis (medial peak systolic velocity (PSV) of $3.77 \pm 1.7 \mathrm{~m} / \mathrm{s}$ and end diastolic velocity (EDV) of $1.32 \pm 0.56 \mathrm{~m} / \mathrm{s}$ ) and morphology of carotid plaque were evaluated by duplex Doppler ultrasonography (DUS) and/or CT. The target lesion was subsequently verified by direct quantitative angiography (QA) just before CAS. The angiographic diameter stenosis (DS) was $84.9 \pm 9.9 \%$ (range: 50-99\%).

All patients were on high-dose statin and dual antiplatelet therapy (aspirin $75 \mathrm{mg}$ daily and clopidogrel $75 \mathrm{mg}$ daily for at least 3 days before the procedure or loading dose of $300 \mathrm{mg}$ of aspirin and clopidogrel the day before the procedure). During CAS unfractionated heparin (100 IU/kg) was used to achieve activating clotting time in a range of 250-300 s. Atropine (1-2 mg i.v.) was administered just before stent implantation to avoid

Table I. Baseline characteristics of patients

\begin{tabular}{|c|c|}
\hline Parameter & Value \\
\hline Number of CAS & 298 \\
\hline Number of patients & 287 \\
\hline Age [years] & $70.5 \pm 8.64$ \\
\hline Men & $203(70.7 \%)$ \\
\hline Hypertension & $268(93.4 \%)$ \\
\hline Hyperlipidemia & $281(98 \%)$ \\
\hline Diabetes & $89(31 \%)$ \\
\hline Active smokers & $144(50.2 \%)$ \\
\hline Coronary artery disease* & $177(61.7 \%)$ \\
\hline Previous myocardial infarction & $74(25.8 \%)$ \\
\hline Previous CABG & 35 (12.2\%) \\
\hline Previous percutaneous coronary artery intervention & $97(33.8 \%)$ \\
\hline Glomerular filtration rate $\left[\mathrm{ml} / \mathrm{min} / 1.73 \mathrm{~m}^{2}\right]$ & $70.1 \pm 19.05$ \\
\hline Previous angioplasty in peripheral territory & $29(10.1 \%)$ \\
\hline $\begin{array}{l}\text { Previous surgical interventions in peripheral terri- } \\
\text { tory }\end{array}$ & $9(3.1 \%)$ \\
\hline Contralateral ICA/CCA occlusion & $24(8.4 \%)$ \\
\hline Contralateral ICA/CCA stenosis > 50\% & $32(11.1 \%)$ \\
\hline Symptomatic lesion ${ }^{\oplus}$ & $89(30 \%)$ \\
\hline Asymptomatic lesion ${ }^{\oplus}$ & $209(70 \%)$ \\
\hline $\begin{array}{l}\text { Transient ischemic attack of ipsilateral hemisphere } \\
\text { in the last } 6 \text { months }\end{array}$ & $22(7.7 \%)$ \\
\hline Stroke of ipsilateral hemisphere in the last 6 months & $57(19.9 \%)$ \\
\hline Ipsilateral amaurosis fugax in the last 6 months & $10(3.5 \%)$ \\
\hline High risk lesion ${ }^{\mu}$ & $237(79.5 \%)$ \\
\hline \multicolumn{2}{|c|}{$\begin{array}{l}{ }^{*} \text { Confirmed by angiography }>50 \% \text { stenosis of at least one coronary artery or } \\
\text { history of percutaneous coronary intervention (PCI) or coronary artery bypass } \\
\text { graft (CABG), CABG - coronary artery bypass graft, ICA - internal carotid artery, } \\
C C A \text { - common carotid artery, "out of all } 298 \text { CAS procedures, "high risk lesion - } \\
\text { echolucent, highly lipidic, ulcerated, "string-sign stenoses", thrombus-contain- } \\
\text { ing lesions, "soft'lesions, i.d. with computed tomography density of < } 60 \mathrm{HU} \text {. }\end{array}$} \\
\hline
\end{tabular}


Table II. The devices utilized during CAS

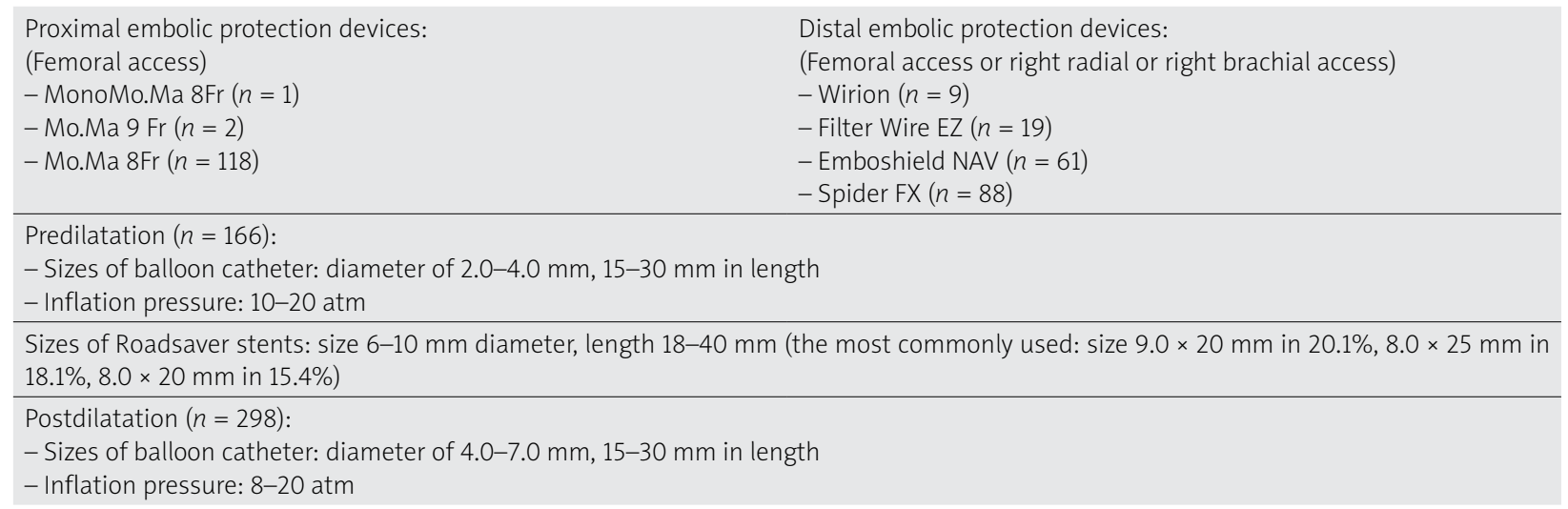

a severe baroreceptor response. Femoral (93.6\%), right radial $(5.7 \%)$ or right brachial $(0.7 \%)$ access was used. The detailed procedural steps including embolic protection device selection and pre/postdilatation balloon sizing have been described previously [11]. The use of an embolic protection device (EPD) was mandatory. In 40.2\% of patients proximal and in $59.7 \%$ of patients distal embolic neuroprotection was applied. The devices used for CAS are presented in Table II.

Direct stenting was performed in 132 (44.2\%) cases whereas in 166 (55.7\%) cases predilatation with a small coronary balloon (2.5-3.5 mm) was required. In all cases postdilatation was performed using usually 4.0-7.0 mm diameter balloons to optimize the angiographic outcome. In each patient angiography of intracranial arteries before and comparatively after the procedure was performed. The most representative examples of DLMCS-supported CAS are shown in Figures 1 and 2.

Patients were discharged 1-2 days after procedure completion with the recommendation of continuation of aspirin, statin (indefinitely) and clopidogrel (for 3 months). In 35 patients with atrial fibrillation vitamin $\mathrm{K}$ antagonists or novel oral anticoagulants were restarted after CAS. As the risk of in-stent restenosis is highest

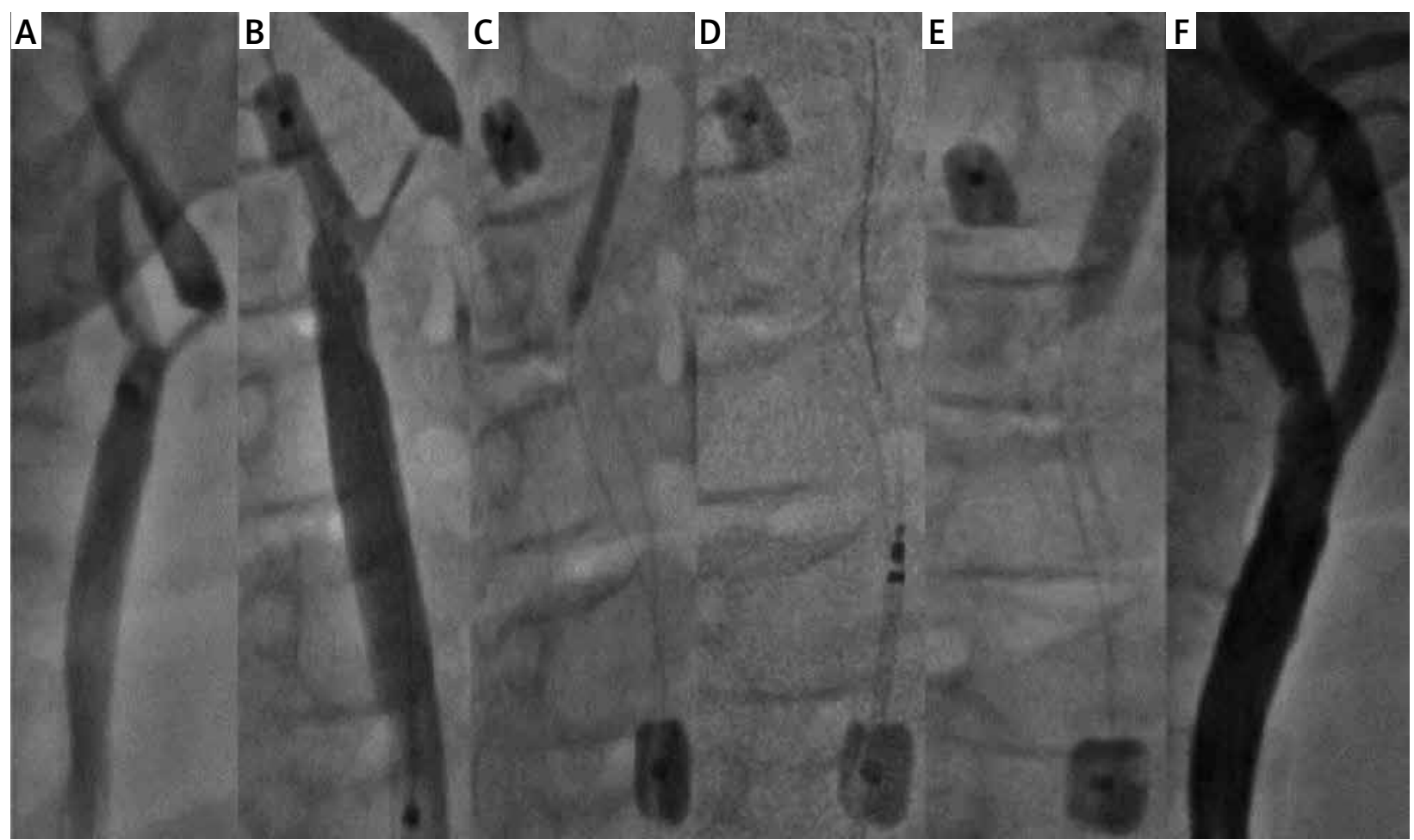

Figure 1. CAS of severe, high risk stenosis of right ICA using Roadsaver stent and Mo.Ma EPD: A - angiography - 90\% RICA stenosis, B - Mo.Ma distal balloon inflated in external carotid artery, C - Both balloons of Mo.Ma system inflated, predilatation with $2.5 \times 25 \mathrm{~mm}$ balloon, D $-8.0 \times 25 \mathrm{~mm}$ Roadsaver stent implantation, $\mathrm{E}$ - postdilatation with $5.0 \times 20 \mathrm{~mm}$ balloon, $\mathbf{F}$ - final angiography showing optimal angiographic result of CAS 


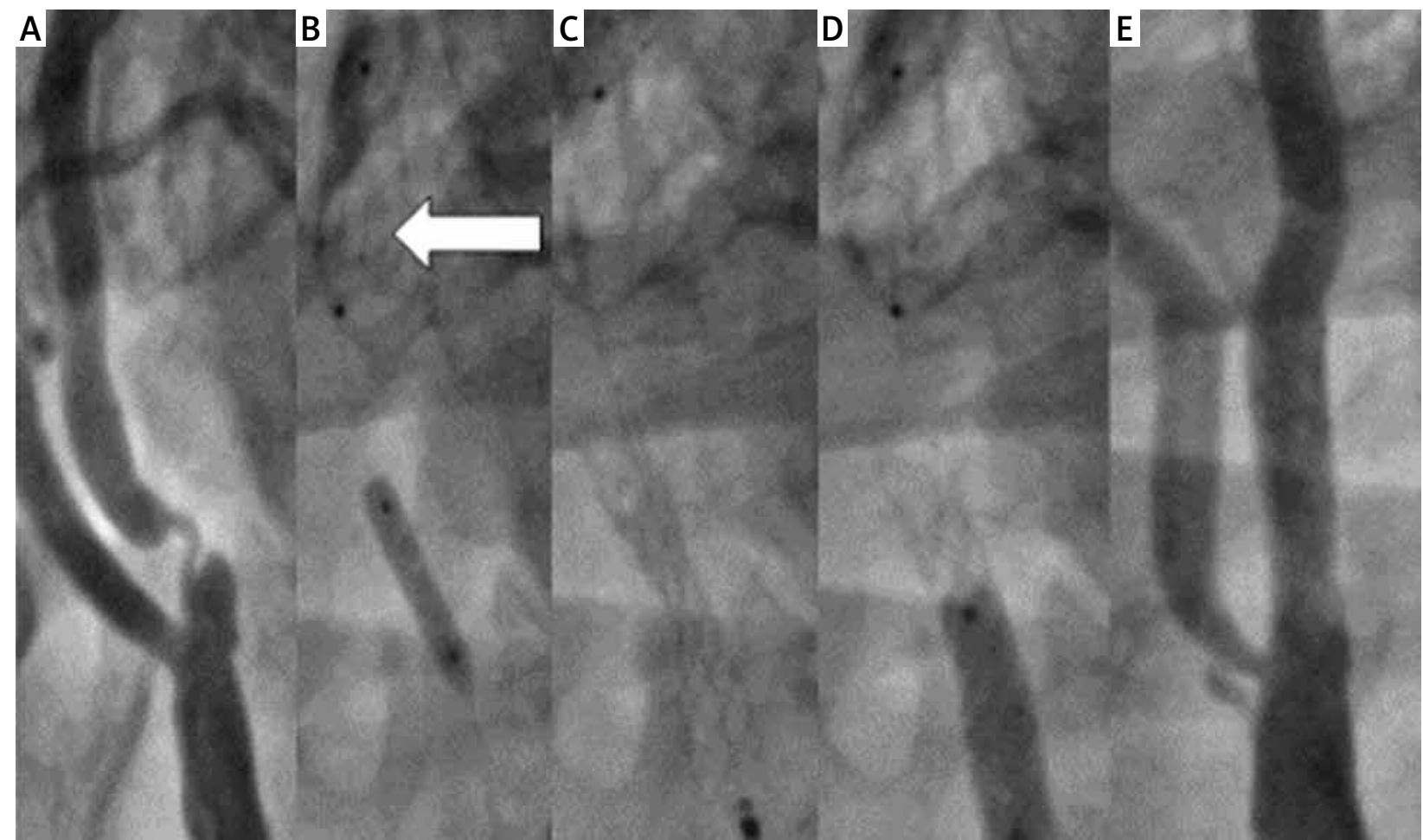

Figure 2. Severe symptomatic lesion of the left ICA and the subsequent steps of CAS using Roadsaver stent and distal EPD-SpiderFX $7 \mathrm{~mm}$, right radial access: A - angiography showing 90\% LICA stenosis, B - opening of the filter in the distal segment of LICA (arrow) and predilatation with $3.0 \times 15 \mathrm{~mm}$ balloon, C-7.0 $\times 18 \mathrm{~mm}$ Roadsaver stent implantation, D - postdilatation with $5.0 \times 20 \mathrm{~mm}$ balloon, E - final angiography showing optimal angiographic result of CAS

in the first year after the initial procedure, clinical and neurological evaluation as well as DUS examination were performed before discharge, after 30 days, 6 months, 12 months and every year afterwards $[11,12]$.

\section{Statistical analysis}

Categorical variables are presented as numbers and percentages. Continuous variables were expressed as mean and standard deviation (SD). Comparison between baseline and post-procedural results (including follow-up assessments) of \%DS, PSV and EDV values were performed using the Wilcox signed-rank test. The log-rank statistic was used to test the differences between symptomatic and asymptomatic subjects. Survival curves were calculated using the Kaplan-Meier method. Two-sided $p$-values $<0.05$ were considered statistically significant. All calculations were done with JMP, Version 14.2.0 (SAS Institute INC., Cary, NC, USA) and using R, Version 3.4.1 (R Core Team. R: A language and environment for statistical computing. R Foundation for Statistical Computing. Vienna, Austria, 2017).

\section{Results}

The Roadsaver stent was successfully delivered and expanded in all cases. The postprocedural residual stenosis was $0-33 \%$ by QA (mean: $11.03 \pm 9.4 \%$ ) vs. $84.9 \pm 9.9 \%$ (range: $50-99 \%)$ before the procedure $(p<0.001)$. Control DUS evaluation at 24-48 $\mathrm{h}$ after stenting revealed a significant PSV/EDV decrease as compared to initial values $(1.3 / 0.31 \pm 0.35 / 0.11 \mathrm{~m} / \mathrm{s}$ vs. $3.77 / 1.32 \pm 1.7 / 0.56$ $\mathrm{m} / \mathrm{s}$ respectively; $p<0.0001)$. Mean PSV/EDV values were $1.2 / 0.34 \pm 0.58 / 0.16 \mathrm{~m} / \mathrm{s}$ at 30 days, $1.2 / 0.4 \pm 0.4 / 0.1 \mathrm{~m} / \mathrm{s}$ at 6 months, $1.3 / 0.5 \pm 0.4 / 1.7 \mathrm{~m} / \mathrm{s}$ at 12 months, $1.3 / 0.4$ $\pm 0.4 / 0.1 \mathrm{~m} / \mathrm{s}$ at 24 months, $1.29 / 0.38 \pm 0.38 / 0.1 \mathrm{~m} / \mathrm{s}$ at 36 months and 1.35/0.40 $\pm 0.35 / 0.10$ at 48 months.

During hospitalization one ipsilateral major and three minor (NIHSS < 5 points [12]) ischemic strokes occurred (1.34\%), and 1 (0.3\%) patient died due to hemorrhagic stroke. Between discharge and 30 days 1 (0.3\%) patient died due to hemorrhagic stroke and 3 (1.0\%) ipsilateral minor strokes occurred - of those 2 were associated with in-stent thrombosis (0.7\%). Thus, the 30-day complication rate was $3.02 \%(n=9)$.

Among patients who died due to hemorrhagic stroke, one case was a consequence of hyperperfusion syndrome (HPS) that occurred 2 days after CAS; the other cause of death has remained unknown and it occurred 21 days after CAS.

Both patients with stent thrombosis were on recommended medications, including dual antiplatelet therapy. The first case of in-stent thrombosis occurred 5 days after CAS in a 76-year-old man, within a $8.0 \times 25 \mathrm{~mm}$ 
stent, and led to total artery occlusion and minor stroke. The second thrombosis occurred 14 days after CAS in a 67-year-old man, within a $9.0 \times 20 \mathrm{~mm}$ stent, and led to subtotal (99\%) artery stenosis and minor stroke. Neurological symptoms receded and the thrombus was dissolved within $24 \mathrm{~h}$ after introduction of continuous i.v. heparin. Additionally, resistance to clopidogrel was diagnosed and the patient was switched to ticagrelor without further signs of recurrent thrombosis.

One and six months DUS follow-up did not show further in-stent thrombus formation.

Eighteen patients died during 4 years of follow-up (6.3\%). Of those, 10 (3.5\%) patients died due to cardiovascular complications (myocardial infarction/sudden cardiac death $(n=9)$, heart failure $(n=1))$, and $2(0.7 \%)$ patients died due to ischemic stroke 33 months and

A

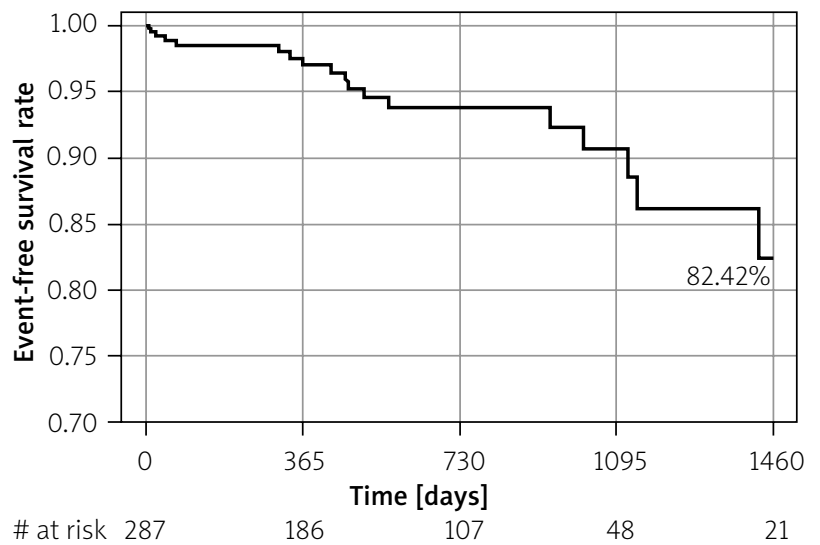

37 months after CAS. In 6 (2.1\%) patients the cause of death remains unknown. Excluding in-stent thrombosis cases, in all stroke patients normal in-stent blood flow was assessed by DUS.

The 4-year follow-up showed $82 \% / 89 \%$ overall survival/stroke-free survival with no significant difference between symptomatic and asymptomatic patients (Figures 3 and 4).

Eleven patients could not be contacted; thus, the lost-to-follow-up rate was 3.8\%.

Seven $(2.3 \%)$ cases of in stent restenosis were observed in a period 5-12 months after CAS, 4 patients underwent successful re-angioplasty using drug-eluting balloons (DEB), 2 cases required self-expandable drug-eluting stent implantation, and in one asymptomatic patient re-angioplasty failed due to a problem with

B

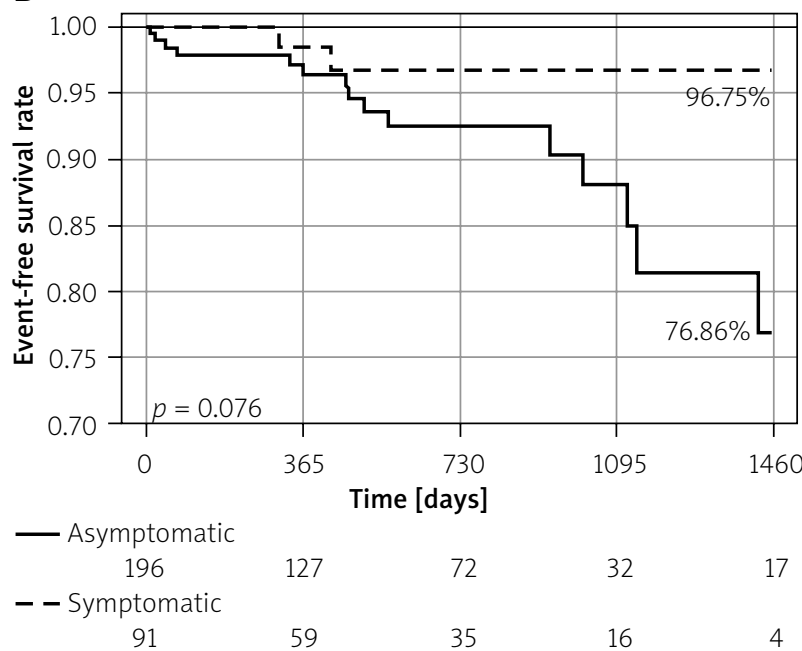

Figure 3. Four-year Kaplan-Meier event free-survival curves for patients undergoing carotid artery stenting with Roadsaver stents. A - Overall survival. B - Death-free survival for the symptomatic and asymptomatic patients

A

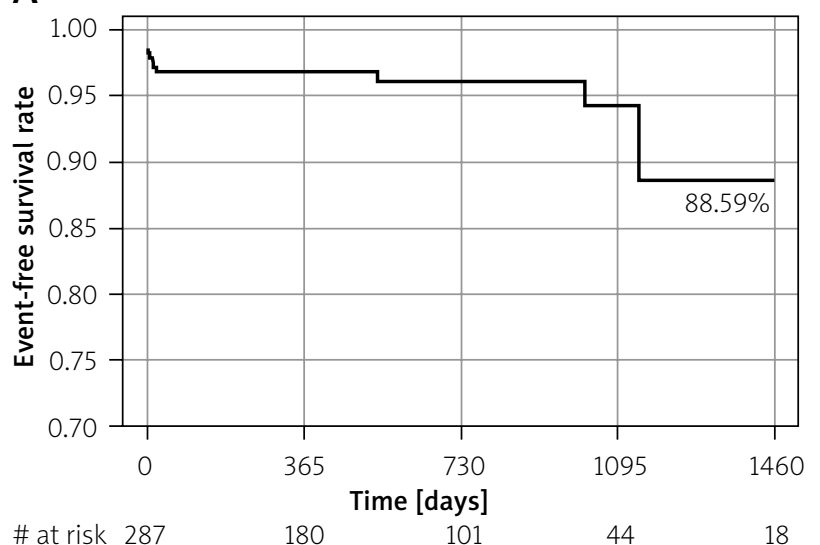

B

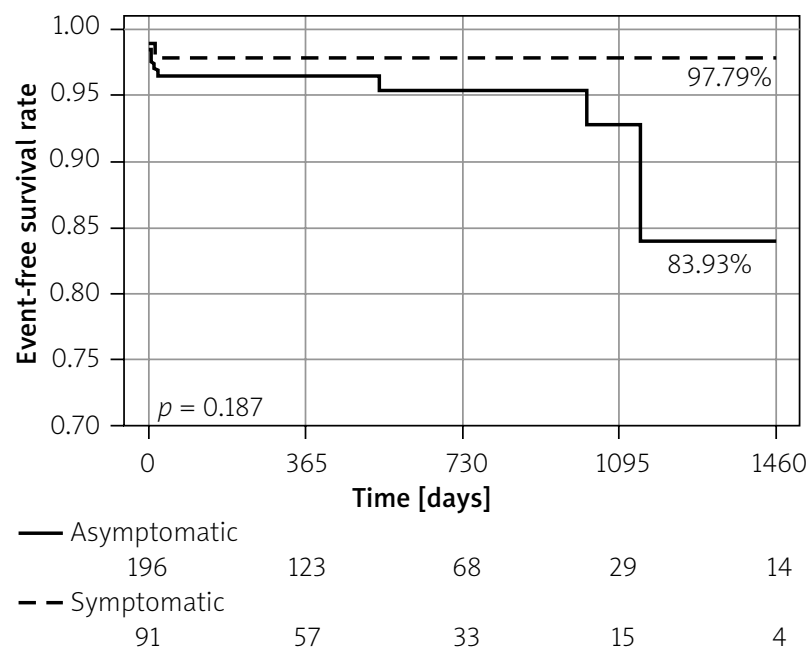

Figure 4. Four-year Kaplan-Meier stroke free-survival curves for patients undergoing carotid artery stenting with Roadsaver stents. A - Stroke-free survival for all patients. B - Stroke-free survival for the symptomatic and asymptomatic patients 
vascular access (Leriche syndrome and unsuccessful radial/brachial access attempt). As the patient was asymptomatic he was qualified for optimal medical treatment.

\section{Discussion}

Technological development is an on-going process. Despite the fact that the majority of stents implanted in the CREST study population were open-cell with single cell area of $11.5 \mathrm{~mm}^{2}$, the 30 -day results were similar to those of the gold standard CEA [3]. As it was previously pointed out, plaque protrusion is an important handicap of first generation stents and may significantly increase the risk of distal embolization. In 2013 a new family of double-layer micromesh-covered stents was introduced. The technology, combining the architecture of open-cell stents (providing optimal flexibility and apposition) with closed cells of micromesh $\left(0.381 \mathrm{~mm}^{2}, 375-500 \mu \mathrm{m}\right.$ Roadsaver or $0.15 \mathrm{~mm}^{2}, 150-180 \mu \mathrm{m}$, CGuard) opened the way to perform CAS offering full anatomical restoration of the vessel and optimal protection against plaque protrusion and distal embolization [2, 10]. Indeed, data on optical coherence tomography (OCT) and IVUS confirm Roadsaver stent optimal wall apposition with no significant plaque protrusion through stent cells [2, 3, 13-15]. Moreover, the diffusion-weighed magnetic resonance imaging (DW-MRI) studies showed low, clinically insignificant intracerebral embolization within 24-48 h after CAS and no new spots of embolization within the next 30 days $[16,17]$. The very low complication rate of $1 \%$ was confirmed by the results of several studies including a total of 550 patients who underwent CAS with implantation of a dual-layer micromesh covered stent (Roadsaver or CGuard) [3, 18-21]. On the other hand, it has been widely discussed that distal embolization may occur at each step of the procedure; thus, the right selection of neuroprotection device is also crucial [11, 22]. Montorsi et al. compared recently the Roadsaver stent with the Carotid Wallstent (single-layer, closed-cell design; Boston Scientific, US) in association with either distal embolic protection (FilterWire EZ, Boston Scientific, US) or proximal embolic protection (Mo.Ma, Medtronic, Italy) in patients with high-risk lipid-rich carotid plaques [23]. CAS performed with the Mo.Ma system gave significantly less microembolic signals in transcranial DUS when combined with the Roadsaver as opposed to the Carotid Wallstent $p=0.043)$. It is also very important that the clear benefit of using the Mo.Ma device was seen when study population was divided into two groups according to type of neuroprotection use - the Mo.Ma system significantly reduced the mean microembolization signal count during consecutive steps of CAS (lesion crossing, stent crossing, stent deployment and post-dilation) on transcranial DUS.

There have been some concerns raised over in-Roadsaver-stent thrombosis. Yilmaz et al. performed a retrospective analysis of data concerning intracranial inter- ventions in the treatment of acute stroke associated with dual-layer micromesh-covered stent CAS and reported a higher risk of acute thrombosis [24]. Although in the study the Roadsaver stent had a significantly higher rate of acute occlusion as compared with the Carotid Wallstent $(p=0.001)$, there might have been some imbalance between the study groups, e.g. significantly more patients from the group of single-layer stent received recombinant tissue plasminogen activator before the procedure and a group of patients with acute stent occlusion had a trend to be treated with smaller stent diameters and had a higher platelet count. The authors did not give information about intraprocedural heparin use and not all patients received dual antiplatelet therapy. Another example of acute thrombosis in DLMCS is given by Casana et al., who describe CGuard stent occlusion $4 \mathrm{~h}$ after implantation to the extracranial part of the internal carotid artery [22]. We registered two cases $(0.7 \%)$ of thrombosis in our center - at days 5 and 12 after the procedure. The thrombosis clinically presented as minor strokes. Although it seems that acute in-Roadsaver stent thrombosis is a rare phenomenon, data on long-term follow-up are not yet available. It is important to note that patients from our registry were symptomatic or with high risk lesions [11], with generalized and advanced atherosclerosis. These factors may also influence the risk of periprocedural complications including cerebral embolization. Another important fact is that both ends of the Roadsaver stent are not covered with a dual-layer micromesh layer. If the atherosclerotic plaque is not completely covered by a micromesh part of the stent (e.g. in severe, disseminated atherosclerosis), there is a risk of plaque mobilization and protrusion. Total death/stroke/myocardial infarction in 30-day follow-up in our center was $3.0 \%$ in total, $1.2 \%$ in symptomatic and $3.8 \%$ in asymptomatic (but with high-risk lesions) patients. Although the complication rate for the asymptomatic group slightly exceeds the threshold of $3 \%$ accepted by guidelines, it is important to remember that all those patients had high-risk carotid artery stenosis (i.e. echolucent, highly lipidic, ulcerated, "string-sign stenoses", thrombus-containing, 'soft' lesions). High-risk plaque has been shown to be associated directly with high risk of embolization during CAS performed using a conventionally designed stent and distal neuroprotection $[25,26]$.

It should also be emphasized that the technical success, periprocedural complications and treatment outcomes depend not only on access to innovative technology and proper selection of patients; the learning curve in CAS procedures cannot be neglected [27].

Although it is still an early period of observation, our work has shown that the risk of significant in-Roadsaver-stent restenosis remains in the acceptable range during 4-year follow-up $(2.3 \%$ as compared to $6.0 \%$ 
reported by CREST investigators [28]). Importantly, it might be presumed that non-mandatory postdilatation in CREST may have influenced the results. However, in comparison to the smallest-cell design Carotid Wallstent postdilated obligatorily with a $4.5-5.5 \mathrm{~mm}$ balloon, still the Roadsaver shows much lower prevalence of restenosis [29].

As the Roadsaver low profile makes both femoral and radial/brachial access available there was no need for use of direct carotid hybrid surgical/endovascular access in our cohort. Even so, it has been demonstrated that direct transcervical access for carotid artery stenting is safe and effective, and may be considered in patients with unfavorable anatomy [30].

There are some limitations of our research. It was a non-randomized study in selected patients. No pre- or post-procedural diffusion-weighed magnetic resonance cerebral imaging was performed to determine the true number of cases of cerebral embolization. There was no intravascular imaging assessing the local effect of stent implantation.

\section{Conclusions}

CAS using the Roadsaver stent for symptomatic and high risk lesions seems to be safe and effective, with a low complication rate and acceptable in-stent restenosis risk in 4-year follow-up.

\section{Conflict of interest}

The authors declare no conflict of interest.

\section{References}

1. Sardar P, Chatterjee S, Aronow HD, et al. Carotid artery stenting versus endarterectomy for stroke prevention: a meta-analysis of clinical trials. J Am Coll Cardiol 2017; 69: 2266-75.

2. Cremonesi A, Castriota F, Secco GG, et al. Carotid artery stenting: an update. Eur Heart J 2014; 36: 1-9.

3. Musialek P, Mazurek A. Percutaneous interventions in carotid atherosclerosis in primary and secondary stroke prevention what is new? Reduction of intra- and post-procedural cerebral embolization with mesh-covered stent. Kardiol Inwazyjna 2017; 12: 43-8

4. Musialek P, Hopkins LN, Siddiqui AH, et al. One swallow does not a summer make but many swallows do: accumulating clinical evidence for nearly-eliminated peri-procedural and 30-day complications with mesh-covered stents transforms the carotid revascularization field. Adv Interv Cardiol 2017; 13: 95-106.

5. Hopf-Jensen S, Marques L, Preiss $M$, et al. Initial clinical experience with the micromesh roadsaver carotid artery stent for the treatment of patients with symptomatic carotid artery disease. J Endovasc Ther 2015; 22: 220-5.

6. Schofer J, Arendt M, Tübler T, et al. Late cerebral embolization after emboli-protected carotid artery stenting assessed by sequential diffusion-weighted magnetic resonance imaging. JACC Cardiovasc Interv 2008; 1: 571-7.

7. de Donato G, Setacci C, Deloose K, et al. Long term results of carotid artery stenting. J Vasc Surg 2008; 48: 1431-41.
8. Bosiers M, de Donato G, Deloose K, et al. Does free cell area influence the outcome in carotid artery stenting? Eur J Vasc Endovasc Surg 2007; 33: 135-41.

9. Pieniązek P, Nowakowski P, Ziaja K, et al. Prospective multicentre study of carotid artery stenting using the MER ${ }^{\text {TM }}$ Stent - the OCEANUS study - 30-day and one-year follow-up results. Adv Interv Cardiol 2020; 16: 1-9.

10. Kedev S, Petkoska D, Zafirowska B, et al. Safety of Slender $5 \mathrm{Fr}$ transradial approach for carosti artery stenting with a novel double-layer micromesh stent. Am J Cardiol 2015; 116: 977-81.

11. Pieniazek P, Musialek P, Kablak-Ziembicka A, et al. Carotid artery stenting with patient - and lesion - tailored selection of the neuroprotection system and stent type: early and 5-year results from a prospective academic registry of 535 consecutive procedures (TARGET-CAS). J Endovasc Ther 2008; 15: 249-62.

12. Armstrong PA, Bandyk DF, Johnson BL, et al. Duplex scan surveillance after carotid angioplasty and stenting: a rational definition of stent stenosis. J Vasc Surg 2007; 46: 460-5.

13. Yakhkind A, MacTaggart RA, Mahesh V, et al. Minor stroke and transient ischemic attack: research and practice. Front Neurol 2016; 7: 86

14. De Donato G, Setacci C, Umemoto T, et al. Commentary; Inside of the interaction between plaque and the stent: optical coherence tomography during carotid stentig J Endovasc Ther 2015; 22: 950-1.

15. Umemoto T, de Donato G, Pacchioni A, et al. Optical coherence tomography assessment of newgeneration mesh-covered stents after carotid stenting. Eurolntervention 2017; 20: 1347-54.

16. Schnaudigel S, Groschel K, Pilgrom SM, et al. New brain lesions after carotid tenting versus carotid endarterectomy: a systemic review of the literature. Stroke 2008; 39: 1911-9.

17. Ruffino MA, Faletti R, Fronda M, et al. Early embolization after carotid artery stenting with mesh-covered stent: role of diffusion-weighed magnetic resonance imaging as pre-procedural predictor and discriminant between intra- and post-procedural events. Cardiovasc Intervent Radiol 2019; 42: 812-9.

18. Bosiers M, Deloose K, Torsello G, et al. The CLEAR-ROAD study: evaluation of a new dual layer micromesh stent system for the carotid artery. EuroIntervention 2016; 12: e671-6.

19. Nerla R, Castriota F, Micari A, et al. Carotid artery stenting with a new-generation double-mesh stent in three high-volume Italian centres: clinical results of a multidisciplinary approach. EuroIntervention 2016; 12: e677-83.

20. Machnik R, Paluszek P, Tekieli L, et al. Mesh-covered (Roadsaver) stent as a new treatment modality for symptomatic or high-risk carotid stenosis. Adv Interv Cardiol 2017; 13: 130-4.

21. Speziale F, Capoccia L, Sirignano P, et al. 30-day results from prospective multi-specialty evaluation of carotid artery stenting using the CGuard MicroNet-covered embolic prevention stent system in real world multicenter clinical practice: the IRON-GUARD study. Eurolntervention 2018; 20: 1714-20.

22. Casana R, Tolva V, Odero Jr A, et al. Safety and efficacy of the new micromesh-covered stent CGuard in patients undergoing carotid artery stenting: early experience from a single centre. Eur J Vasc Endovasc Surg 2017; 54: 681-7.

23. Montorsi P, Caputi L, Galli S, et al. Carotid Wallstent versus Roadsaver stent and distal versus proximal protection on cerebral microembolization during carotid artery stenting. JACC CardiovasC Interv 2020; 13: 403-14.

24. Yilmaz U, Körner H, Mühl-Benninghaus R, et all. Acute occlusions of dual-layer carotid stents after endovascular emergency treatment of tandem lesions. Stroke 2017; 48: 2171-5. 
25. Biasi GM, Froio A, Diethrich EB, et al. Carotid plaque echolucency increases the risk of stroke in carotid stenting: the Imaging in Carotid Angioplasty and Risk of Stroke (ICAROS) study. Circulation 2004; 110: 756-62.

26. Schmidt A, Diederich KW, Scheinert S, et al. Effect of two different neuroprotection systems on microembolization during carotid artery stenting. J Am Coll Cardiol 2004; 44: 1966-9.

27. Lin PH, Bush RL, Peden E, et al. What is the learning curve for carotid artery stenting with neuroprotection? Analysis of 200 consecutive cases a tan academic institution. Perspect Surg Endovasc Ther 2005; 17: 113-23.

28. Lal B, Beach K, Roubin G, et al. Restenosis after carotid artery stenting and endarterectomy: a secondary analysis of crest, a randomised controlled trial. Lancet Neurol 2012; 11: 755-63.

29. Tekieli L, Musiałek P, Kabłak-Ziembicka A, et al. Severe, recurrent in-stent carotid restenosis: endovascular approach, risk factors. Results from a prospective academic registry of 2637 consecutive carotid artery stenting procedures (TARGET-CAS). Adv Interv Cardiol 2019; 15: 465-71.

30. Sfyroeras G, Moulakakis KG, Markatis F, et al. Results of carotid artery stenting with transcervical access. J Vasc Surg 2013; 58: 1402-7. 